\title{
A study on the influence of ionic strength on the elution behaviour of membrane organic foulant using advanced separation tools
}

\author{
H.K. Shon ${ }^{\mathrm{a}, *}$, S. Puntsho ${ }^{\mathrm{a}}$, K. Chon ${ }^{\mathrm{b}}$, R. Aryal ${ }^{\mathrm{a}}$, S. Vigneswaran ${ }^{\mathrm{a}}$, In S. Kim ${ }^{\mathrm{b}}$, J. Cho ${ }^{\mathrm{b}}$ \\ ${ }^{a}$ Faculty of Engineering and IT, University of Technology, Sydney (UTS), P.O. Box 123, Broadway, NSW 2007, Australia \\ ${ }^{b}$ Environmental Science and Technology, Gwangju Institute of Science and Technology, Gwangju, Korea \\ Tel. +61 2 9514-2641; Fax.+61 2 9514-2633; email: hkshon@eng.uts.edu.au
}

Received 7 April 2009; Accepted 31 August 2009

\begin{abstract}
A B S T R ACT
Although membrane technology has become a reliable and viable alternative for water and wastewater treatment, membrane fouling is a serious challenge. In this case study, we report application of different techniques to extract foulant from the hollow fibre membrane and characterize the foulant into various components of organic, inorganic and different fractions. The organic foulant was subjected to high-pressure size exclusion chromatography (HPSEC) and flow field-flow fractionation (FIFFF) analysis to study the influence of ionic strength on its elution behaviour using $\mathrm{NaCl}$ and $\mathrm{CaCl}_{2}$ as carrier solutions. It was observed that an increase in ionic strength delayed the elution time of both the organic foulant and the Na-salt of Polysterene sulphone (PSS) with HPSEC. However, no such effect was observed with FlFFF analysis. Such study is significant because the characteristics of the membrane organic foulant are believed to be influenced by the carrier ionic conditions and $\mathrm{pH}$ and, therefore their subsequent interaction with the membrane and membrane fouling process. However with FlFFF, whether the influence of carrier ionic strength is limited to certain type of ionic carriers or certain groups of natural organic matter is a scope for further research.
\end{abstract}

Keywords: Flow field-flow fractionation (FlFFF); High performance size exclusion chromatography (HPSEC); ionic strength; Membrane fouling; Organic foulant

\section{Introduction}

Amongst the numerous technologies, membrane filtration has emerged as a reliable and viable water and wastewater treatment alternative. Membrane offers a versatile approach in meeting multiple water quality objectives, such as control of organic, inorganic and microbial contaminants. However membrane fouling has been one of the most significant hurdles of membrane technology. Membrane fouling not only decreases permeate flux but the efforts to reduce fouling and clean up foulants results in reduced treatment efficiency and high- production cost [1,2]. Unfortunately,

*Corresponding author.

Presented at CESE-2009, Cha doi: 10.5004/dwt.2009.8ŚR membrane fouling remains inevitable since the target compounds for removal are the ones that cause membrane fouling.

The membrane flux decline has been described due to various factors such as pore blocking, adsorption, formation of a gel/cake layer, concentration polarization and biofouling $[2,3]$ all of which relates to the variety of physico-chemical properties of the different colloidal and dissolved organic matter (DOC) present in the water [4]. High-pressure size exclusion chromatography (HPSEC) is a widely used technique in the characterization of organic matter in terms of molecular weight distribution (MWD) [5]. In HPSEC, a porous gel material is used in the column to fractionate the samples based on its hydrodynamic molecular size and its fractionation is limited by size exclusion range of the separation column. 
Flow field-flow fractionation (FlFFF) is another versatile and well established separation techniques adaptable to separate and characterize an enormous assortment of macromolecular and particulate materials [6-9]. The basic theory of FlFFF has been presented in detail elsewhere $[6,7,10-12,13-15]$. In FlFFF, a cross flow is applied as a field perpendicular to the horizontal laminar flow in the channel with fixed dimensions. FlFFF and cross-flow filtration bears many similarities as both techniques use membrane and the cross-flow. The applied field lowers the different sample solute components to the bottom membrane however this applied force is resisted by the upward and back diffusion until equilibrium is reached. The laminar flow in the channel forces the solutes to move along the channel which has a parabolic velocity profile. The separation of different solutes in this FlFFF system is based solely on the differences in solute diffusion coefficients and Stokes radii. The basic measurement parameter in FIFFF is the average residence time of the solute $[2,13]$ which are directly related to the diffusion coefficient and Stokes radii.

Although the techniques under which HPSEC and FlFFF fractionate natural organic matter (NOM) are quite different, each has its own limitations. HPSEC uses a porous gel with a controlled pore size distribution to separate molecules while FIFFF uses hydrodynamic and molecular diffusion principles to separate molecules on the basis of molecular size [5]. The use of gel surfaces in HPSEC is affected by factors such as ionic strength, charge, molecular structures, steric effects and hydrophobicity [16]. This is one reason why the solute-gel interactions in SEC technique have often been criticized. Compared with Fl-FFF, HPSEC can measure only dissolved NOM (less than $0.45 \mu \mathrm{m}$ ) and is a size-dependent separation, rather than the hydrodynamic size. The underlying classical application of FlFFF as the separation technique implies that, at equilibrium, retention should be a sole function of upward diffusion and the applied downward field. However in reality, the other potential attractive and repulsive interactions (electrostatic and van der Waal's forces) may act in presence of the membrane wall surface which could have a significant influence on the diffusivity of the solute. This perturbation is often assumed as one reason for the deviation of the actual results from the theoretical ones. However, what is considered a problem in the classical FIFFF analysis is also an opportunity in the field of membrane science to investigate and correlate this solutionmembrane interactions with membrane fouling [2].

Studies have been reported about the effect of ionic strength and $\mathrm{pH}$ on the molecular size distribution of organic matter by altering their functional groups and ionic/electrical interactions [7,12,17-24]. However, most of these studies were limited to organic models such as humic substances to study membrane fouling. The objectives of this particular study are firstly to report the different techniques that can be applied to extract the membrane foulant from the membrane for the characterization and secondly to evaluate the elution behaviour of the foulant when subjecting to HPSEC and FIFFF fractionation at various ionic strength. The authors believe that such study will shed more light in understanding the behaviour of membrane organic foulant under various ionic strengths and its possible impact on the membrane fouling process.

\section{Experimental methodology}

\subsection{Extraction of membrane foulant}

The organic/inorganic foulant was extracted from polyvinylidene fluoride (PVDF) hollow fiber microfiltration with a filter size of $0.1 \mu \mathrm{m}$ after 18 months of operation. This membrane came from a drinking water treatment plant operated in Han River in Korea. The foulant was extracted from the membrane fiber by desorbing in three different solutions: deionized (DI) water, acid $(0.1 \mathrm{~N} \mathrm{HCl})$ and caustic $(0.1 \mathrm{~N} \mathrm{NaOH})$ solutions. Membrane fibers of known sizes were cut into small pieces and soaked in each solution for 1 day and then ultrasonicated for 180 minutes in a typical laboratory sonication bath (Sonicare, SA, Australia). Acidic solution is typically used to extract inorganic foulants while caustic solution is commonly used to remove organic foulant $[25,26]$. The organic foulant was then diluted with DI water up to $20 \mathrm{mg} / \mathrm{L}$ concentration. All the reagents used in this extraction were of analytical grade.

\subsection{Characteristics of membrane foulant}

Dissolved organic carbon (DOC) and total nitrogen (TN) were analyzed using TOC- $\mathrm{V}_{\mathrm{CPH}}$ (TNM-1) (Shimadzu, Japan). The inorganic elements were analysed using inductively coupled plasma mass spectrometry (ICP-MS) (7500cs, Agilent, USA). The dialysis was performed with Spectra/Por-3 regenerated cellulose dialysis membrane bag (molecular weight cut-off 3500 daltons). The dialysis membrane was washed by soaking it in $4 \mathrm{~L}$ of DI water for 24 hours. The foulant sample was acidified with $\mathrm{HCl}$ to $\mathrm{pH} 1$ and placed in the pre-washed dialysis membrane bag. It was dialyzed for 8 hours (each time) against three $4 \mathrm{~L}$ portions of $0.1 \mathrm{~N} \mathrm{HCl}$ (to remove salts and low $\mathrm{MW}$ of the organic foulant) followed by dissolving in $4 \mathrm{~L}$ of HF $(0.2 \mathrm{~N})$ until disappearance of silica gel precipitate. Finally, it was dialyzed for 12 hours (each time) against two $4 \mathrm{~L}$ portions of DI water. This is to remove residual HF and fluosilicic acid. Finally, the foulant was taken out of the dialysis membrane from the last $4 \mathrm{~L}$ of dialysate 
of DI water and measured for its DOC content. This represents the foulant colloidal matter (with molecular weight range from 3500 dalton to $0.45 \mu \mathrm{m}$ ).

XAD-8 and XAD-4 resins were used for fractionating organic foulant into hydrophobic organic matter (XAD-8 adsorbable; mostly hydrophobic acids with some hydrophobic neutrals), transphilic organic matter (XAD-4 adsorbable; hydrophilic bases and neutrals) components. The remaining fraction escaping the XAD-4 was the hydrophilic component.

\subsection{Carrier solutions and Na-salt PSS standards}

Sodium chloride $(\mathrm{NaCl})$ and calcium chloride $\left(\mathrm{CaCl}_{2}\right)$ of three different ionic concentrations $(0.01,0.1$ and $0.5 \mathrm{M}$ ) were used as carrier solutions and their significance lies in the fact that these ions form the major part of the water in desalination using membranes. The solutions were prepared using pure $\mathrm{NaCl}$ and $\mathrm{CaCl}_{2}$ in a clean standard $2 \mathrm{~L}$ beaker. The salt was weighed in a high-precision standard digital balance, mixed with $2 \mathrm{~L}$ of deionized water and stirred using magnetic stirrer for about 10 minutes. The carrier was then filtered in a $0.45 \mu \mathrm{m}$ microfilter using vacuum suction before being used as mobile phase. The characteristics of the carrier solutions are shown in Table 1.

Sodium salt of Polystyrene sulfonates-PSS (from Polysciences, Inc., PA, USA) of four different MW (1800, 4600,8000 and $18000 \mathrm{Da}$, as provided by the manufacturer with poly dispersity of 1.1), were used as calibration standards for HPSEC and FlFFF. Na-salt of PSS has been well characterised in terms of molecular radii and diffusivity. Furthermore, it has high-aqueous solubility, a non-ionic monodisperse molecular size distribution (supplier report) and low potential for interaction with or adsorption to charged membrane surface. The Na-salt of PSS standards were diluted with deionized water (MilliQ water) to make concentration of 20 ppm. All the experiments using HPSEC and FlFFF were carried out at ambient laboratory temperatures of about $25^{\circ} \mathrm{C}$.

\subsection{HPSEC operations}

MWD analysis of organic foulant was carried out using HP-SEC (Shimadzu, Japan) which consisted of column (Protein-Pak 125, Waters, USA) with fluorescence detector (RF-10A, Shimadzu, Japan). An SEC column was used consisting of glycol-functionalized silica gel (Protein-pak 135, Waters Corp., USA). A flow rate of $0.7 \mathrm{~mL} / \mathrm{min}$ was used. System calibration was performed with PSS standards of 20 ppm concentrations. All injection volumes of the samples were $100 \mu \mathrm{L}$. The concentrations of carrier solvents were $0.01 \mathrm{M} \mathrm{NaCl}$ and $0.1 \mathrm{M} \mathrm{CaCl}_{2}$.

\subsection{FlFFF operations}

FlFFF experiments were carried out using F-1000 Universal Fractionator (PostNova Analytics LLC, Salt Lake City) with channel dimensions of $29.8 \mathrm{~cm}$ (tip to tip) in channel length, $2 \mathrm{~cm}$ in channel width and $0.025 \mathrm{~cm}$ in channel thickness. The other features included computerized data acquisition system, pressure regulator and bubble trap. The commercialized membrane regenerated cellulose (Z-MEM-AQU-101, Postnova Analytics, Germany) with a MWCO of $\sim 1 \mathrm{kDa}$ was used as a channel wall. The membrane was coated with silicon around the active membrane area for sealing the FIFFF channel. The detection system consisted of fluorescence detector (RF-10AXL, Shimadzu, Japan) with excitation of $278 \mathrm{~nm}$ and the emission of $353 \mathrm{~nm}$. The sample was injected using $50 \mu \mathrm{L}$ of sample loop (Rheodyne Corporation, CA, USA). Sodium azide $\left(0.1 \mathrm{mM} \mathrm{NH}_{3}\right)$ was used as bactericide with the $\mathrm{NaCl}$ and $\mathrm{CaCl}_{2}$ carrier solutions. All the experiments were carried out at channel flow rate of $0.7 \mathrm{~mL} / \mathrm{min}$ and cross flow rate of $3.0 \mathrm{~mL} / \mathrm{min}$.

\section{Results and discussions}

\subsection{Characteristics of membrane foulant}

The adsorbed organic foulants of the fouled membrane surfaces were extracted and analysed by

Table 1

Conductivity of the carrier solutions under different ionic strength.

Conductivity of eluent for HPSEC

\begin{tabular}{llll}
\hline Eluent & Conductivity & Eluent & Conductivity \\
\hline DI water & $0.55 \mu S / \mathrm{cm}$ & DI water & $0.55 \mu \mathrm{\mu S} / \mathrm{cm}$ \\
$0.01 \mathrm{M} \mathrm{NaCl}$ & $1.159 \mathrm{mS} / \mathrm{cm}$ & $0.01 \mathrm{M} \mathrm{CaCl}_{2}$ & $2.057 \mathrm{mS} / \mathrm{cm}$ \\
$0.1 \mathrm{M} \mathrm{NaCl}$ & $10.38 \mathrm{mS} / \mathrm{cm}$ & $0.1 \mathrm{M} \mathrm{CaCl}_{2}$ & $17.39 \mathrm{mS} / \mathrm{cm}$ \\
$0.5 \mathrm{M} \mathrm{NaCl}$ & $45.4 \mathrm{mS} / \mathrm{cm}$ & $0.5 \mathrm{M} \mathrm{CaCl}_{2}$ & $71.0 \mathrm{mS} / \mathrm{cm}$ \\
\hline
\end{tabular}


washing the membranes with DI water, $0.1 \mathrm{~N} \mathrm{NaOH}$ and $0.1 \mathrm{~N} \mathrm{HCl}$ solution (Table 2). The concentration of organic matter and TN was averaged from different parts of the hollow fibre membrane. The concentrations of membrane organic foulant collected through DI water, $\mathrm{NaOH}$ and $\mathrm{HCl}$ desorption were $0.024,0.233$ and $0.052 \mathrm{mg} / \mathrm{cm}^{2}$ respectively. Here, $\mathrm{cm}^{2}$ represents outer membrane surface area. It was observed that $\mathrm{NaOH}$ comparatively provided the best desorption of membrane organic foulant and the concentration of the desorbed foulant with DI water was 9.7 times lower than that with $\mathrm{NaOH}$ solution. The concentrations of TN desorbed with DI water, $\mathrm{NaOH}$ and $\mathrm{HCl}$ solution were $0.002,0.016$ and $0.052 \mathrm{mg} / \mathrm{cm}^{2}$, respectively. Although TN is an inorganic compound, $\mathrm{NaOH}$ soaking showed the highest concentration. This is due to organic nitrogen sources which were present in protein, soluble microbial polymer, etc.

The organic colloidal portion from the membrane foulant was also determined (Table 2). Interestingly, the organic matter harvested from DI water desorption included the highest portion of the colloidal organic foulant (up to $82 \%$ ), while the colloidal organic foulant from $\mathrm{NaOH}$ was almost half $(38 \%)$. This result implies that the organic foulant from $\mathrm{NaOH}$ dissolves the majority of organic foulant due to hydrolysis by high $\mathrm{pH}$.

Table 3 shows the inorganic components of the fouled membrane with different solution washing. In general, the $\mathrm{HCl}$ washing desorbed most of inorganic compounds ( $\mathrm{Al}, \mathrm{Ca}, \mathrm{Fe}, \mathrm{Mg} \mathrm{Mn}$ and $\mathrm{Zn}$ ), while $\mathrm{Cu}$ and $\mathrm{K}$ compounds were well desorbed in the $\mathrm{NaOH}$ solution. The high concentration of $\mathrm{Cu}$ and $\mathrm{K}$ in $\mathrm{NaOH}$ solution was possibly due to their origin or complexation from organic matter. The analysis of the inorganic components of the membrane foulant using ICP-MS indicated that calcium and potassium consisted of the highest inorganic elements followed by manganese and aluminium. These compounds are generally found as a major foulant during membrane filtration [27-30].

The hydrophobic and the hydrophilic organic fractions were determined in the membrane foulant with different washing solutions (Table 4). Hydrophilic fraction, which includes polysaccharide, alkyl alcohol, amide, alkyl amine and amino acid, mainly comprised in the membrane foulant up to more than $50 \%$. It was thus clear from the results that the major membrane organic foulant was made up mainly of hydrophilic fraction followed by hydrophobic and transphilic. However, the highest percentage desorption of each fraction showed different trends. Hydrophobic, hydrophilic and transphilic compounds indicated the highest desorption by DI water, $\mathrm{HCl}$ and $\mathrm{NaOH}$ washing, respectively.

\subsection{Effect of $\mathrm{NaCl}$ and $\mathrm{CaCl}_{2}$ ionic strength using HPSEC}

The chromatogram of the organic foulant from HPSEC analysis under different ionic strength of $\mathrm{NaCl}$ and $\mathrm{CaCl}_{2}$ are shown in Fig. 1. The general trend observed with both $\mathrm{NaCl}$ and $\mathrm{CaCl}_{2}$ carriers was the increase in the elution time of the foulant at higher ionic strength. This increased elution time may be explained due to the alteration of surface characteristics (charge and structures) of the foulant organic particles with the change in ionic concentration. Many earlier studies have reported the influence of $\mathrm{pH}$ and ionic strength on the molecular size distribution of NOM and their increased surface electrostatic interactions $[7,12,17-24]$. At higher

Table 2

Organic, TN concentration and colloidal NOM fraction of membrane foulant.

\begin{tabular}{lllll}
\hline Extraction solution & $\begin{array}{l}\text { Conductivity } \\
(\mathrm{mS} / \mathrm{cm})\end{array}$ & $\mathrm{NOM}$ & $\mathrm{TN}$ & Colloidal NOM \\
\cline { 3 - 4 } & & $\mathrm{mg} / \mathrm{cm}^{2}$ & $\mathrm{mg} / \mathrm{cm}^{2}$ & \\
\hline DI water & 0.025 & 0.024 & 0.002 & $82 \%$ \\
$0.1 \mathrm{~N} \mathrm{NaOH}$ & 9.883 & 0.233 & 0.016 & $38 \%$ \\
$0.1 \mathrm{~N} \mathrm{HCl}$ & 9.677 & 0.052 & 0.005 & $44 \%$ \\
\hline
\end{tabular}

Table 3

Inorganic concentration of membrane foulant. All units in $\mu \mathrm{g} / \mathrm{cm}^{2}$.

\begin{tabular}{lllllllrr}
\hline Extraction solution & $\mathrm{Al}$ & $\mathrm{Ca}$ & $\mathrm{Cu}$ & $\mathrm{Fe}$ & $\mathrm{K}$ & $\mathrm{Mg}$ & $\mathrm{Mn}$ & $\mathrm{Zn}$ \\
\hline $\mathrm{DI}$ & 0.140 & 21.283 & 0.080 & 0.047 & 1.777 & 1.853 & 0.393 & 0.447 \\
$0.1 \mathrm{~N} \mathrm{NaOH}$ & 0.350 & 17.197 & 0.190 & 0.043 & 15.613 & 0.323 & 0.253 & 0.873 \\
$0.1 \mathrm{~N} \mathrm{HCl}$ & 9.527 & 24.510 & 0.073 & 0.073 & 11.937 & 2.287 & 10.773 & 2.213 \\
\hline
\end{tabular}


Table 4

Characterization of organic foulant based on their structures.

\begin{tabular}{llll}
\hline & \multicolumn{3}{c}{ NOM fraction (\%) } \\
\cline { 2 - 4 } & Hydrophobic & Hydrophilic & Transphilic \\
\hline DI & 38 & 50 & 12 \\
$0.1 \mathrm{~N} \mathrm{NaOH}$ & 29 & 48 & 23 \\
$0.1 \mathrm{~N} \mathrm{HCl}$ & 33 & 53 & 15 \\
\hline
\end{tabular}
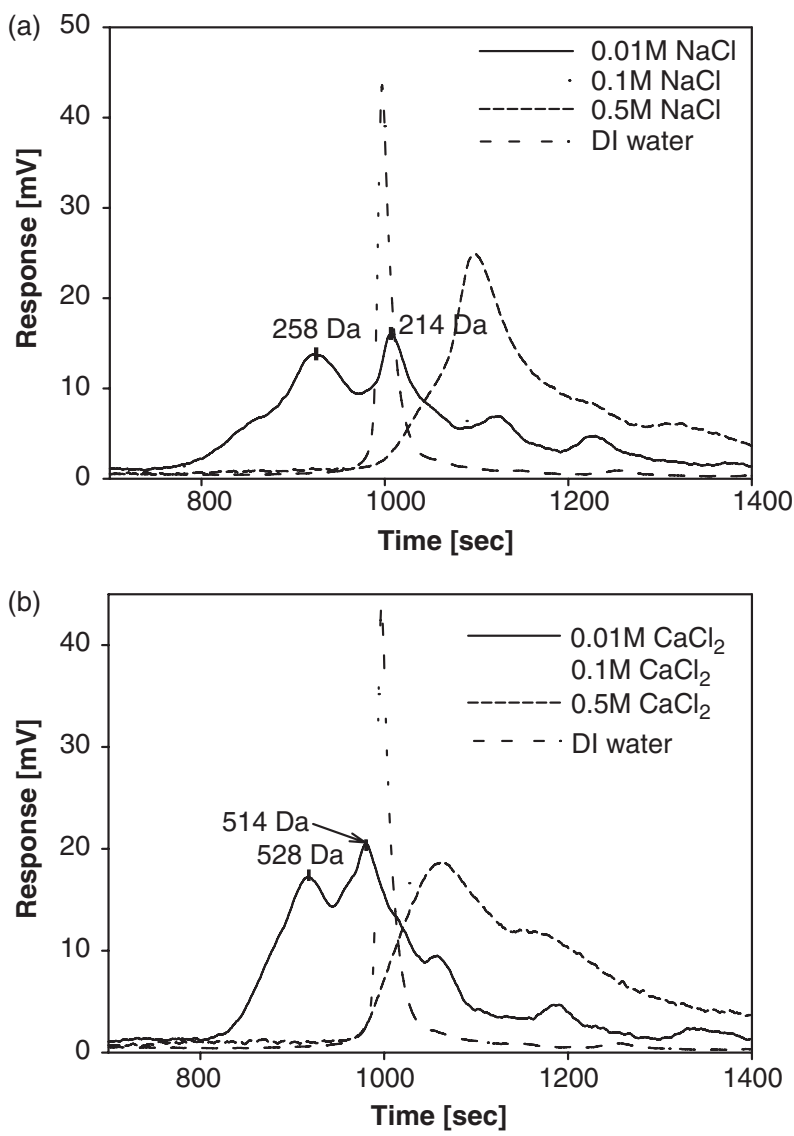

Fig. 1. HPSEC chromatogram of membrane organic foulant under different ionic concentrations. (a) With $\mathrm{NaCl}$ and (b) With $\mathrm{CaCl}_{2}$ solutions. Note that the peak intensity for DI water has been reduced by a factor of 4 .

ionic strength, it is generally believed that the size and shape of the NOM particles decreases due to change in particle shape from linear to more coiled structures $[24,31,32]$. Separation of NOM using gel materials in SEC column is based on the molecular sizes [5] and change in sizes of the NOM particle therefore distort the normal elution time. With NOM particles becoming coiled in shape and smaller in molecular size, adsorption or electrostatic interaction with SEC gel surface increases and consequently delay the elution time.
The results of the organic foulant were also compared using Na-salt of PSS as the calibration standards. From Fig. 2, it is quite clear that the elution time of the Na-salt PSS standards also increased at higher ionic concentrations under both $\mathrm{NaCl}$ and $\mathrm{CaCl}_{2}$ carriers, which is consistent with the earlier results with organic foulant. It may also be significant to note here that there were no distinct differences observed between $\mathrm{NaCl}$ and $\mathrm{CaCl}_{2}$ as carrier solutions in terms of elution time for both organic foulant and PSS standards. Another notable observation made was that, at higher ionic strength, the organic foulant depicted a narrower distribution curve unlike at lower concentrations $(0.01 \mathrm{M})$ where foulant generally appeared heterogenous and broadly dispersed. However with DI water, the distribution displayed was sharp and narrow.

\subsection{Effect of $\mathrm{NaCl}$ and $\mathrm{CaCl}_{2}$ ionic strength on membrane organic foulant using FlFFF}

Figure 3 shows the FlFFF factograms of the organic foulant under different ionic strength of $\mathrm{NaCl}$ and $\mathrm{CaCl}_{2}$
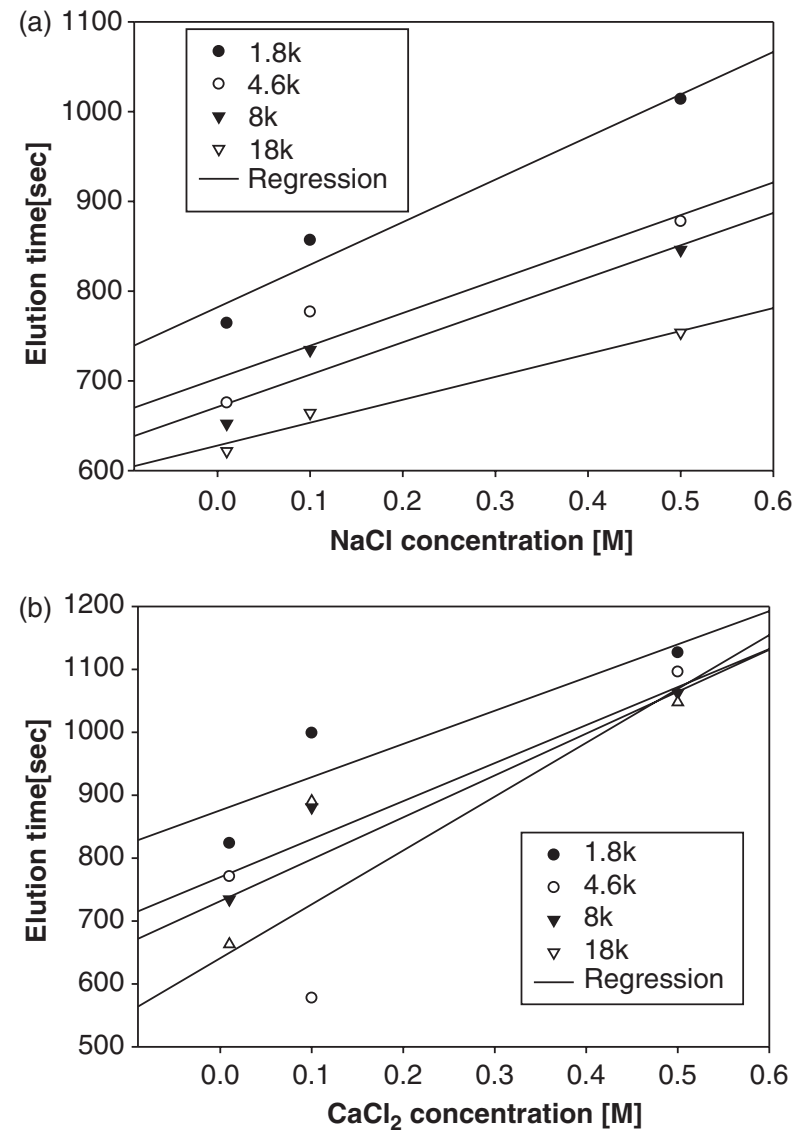

Fig. 2. Elution time of Na-salt PSS standards in HPSEC at different ionic strength. (a) With $\mathrm{NaCl}$ and (b) $\mathrm{CaCl}_{2}$ solutions. 

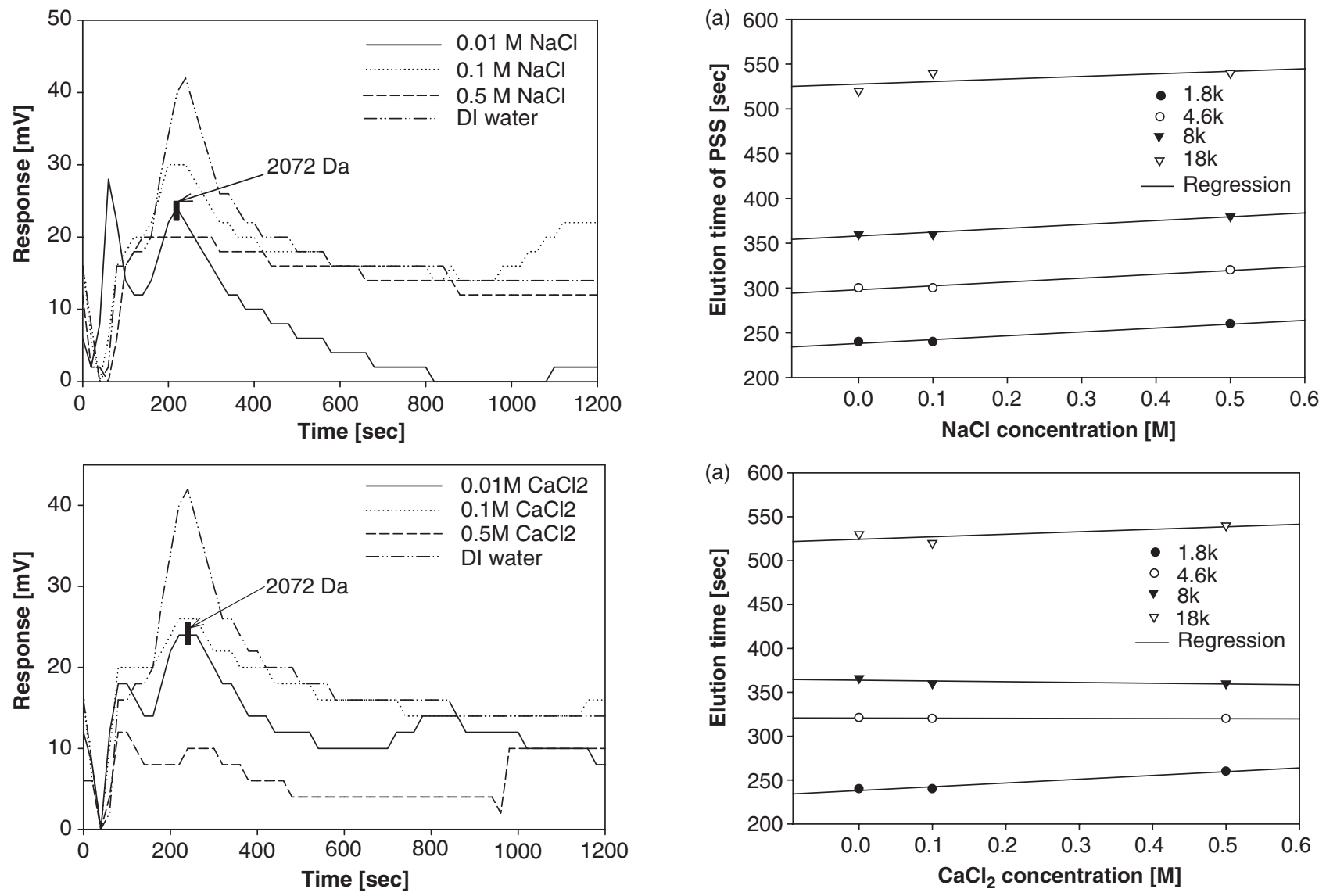

Fig. 3. FlFFF factogram of membrane organic foulant under different ionic concentrations. (a) With $\mathrm{NaCl}$ and (b) $\mathrm{CaCl}_{2}$ solutions. Note that the intensity for all conditions has been magnified by factor of 4 . Cross flow $3.0 \mathrm{~mL} / \mathrm{min}$; Channel flow rate of $0.7 \mathrm{~mL} / \mathrm{min}$.

solutions. The intensities were magnified by a factor of 4 in order to improve the plot resolution. Unlike the HPSEC results above, no significant shift in the elution time of the organic foulant was observed with the change in ionic strength of the FlFFF carrier solutions. The shape of the FlFFF factogram also did not deviate much with the change in the ionic strength of the carrier solutions except for their peak intensities. Similar observations in the elution time were made with Na-salt PSS standards (Fig. 4). Our observation with organic foulant is consistent with the earlier work by Moon et al. [24] where they reported no significant shift in retention time of the river $\mathrm{NOM}$ with change in $\mathrm{KCl}$ ionic concentrations. However, on the contrary, they observed a significant shift in elution time of Na-salt PSS standards when ionic strength of the $\mathrm{KCl}$ solution was changed. Several earlier works have also reported about the increase of elution time with the increase in ionic strength using FIFFF $[7,8,23]$. It is believed that the ionic strength of the carrier solution plays a vital role in the diffusivity and migration of particles at equilibrium height above the

Fig. 4. Variation in FlFFF retention time of Na-salt PSS standards under different ionic strength using $\mathrm{CaCl}_{2}$ solutions. (a) With $\mathrm{NaCl}$ and (b) $\mathrm{CaCl}_{2}$ solutions. Cross flow $3.0 \mathrm{~mL} / \mathrm{min}$; Channel flow rate of $0.7 \mathrm{~mL} / \mathrm{min}$.

FIFFF membrane wall surface and therefore their elution time $[13,17,33]$. The contradictory results pose a question whether the influence of carrier ionic strength in FlFFF is limited to certain type of ionic carriers or certain groups of natural organic matter and this will be an interest for future research.

\section{Conclusion}

The membrane foulant from the hollow fibre MF membrane was extracted by adopting DI, $0.1 \mathrm{~N} \mathrm{NaOH}$ and $0.1 \mathrm{~N} \mathrm{HCl}$ desorption techniques. The membrane foulant was then characterized into its various components of organic, inorganic and different fractions. $\mathrm{NaOH}$ desorption was the best extraction method except for colloidal NOM where DI provided the best washing and certain inorganic elements such as $\mathrm{Al}, \mathrm{Ca}, \mathrm{Mg}, \mathrm{Mn}$ and $\mathrm{Zn}$ by $\mathrm{HCl}$ desorption. The foulant also showed the highest concentrations of $\mathrm{Ca}$ and $\mathrm{K}$ followed by $\mathrm{Mn}$ and $\mathrm{Al}$ which are considered the usual and major membrane foulant. The characterization of the foulant into different 
fractions indicates that the membrane foulant was made up mainly of hydrophilic fraction followed by hydrophobic and transphilic fraction. The influence of ionic strength of the carrier solutions $\left(\mathrm{NaCl}\right.$ and $\left.\mathrm{CaCl}_{2}\right)$ on the elution time of the membrane organic foulant was studied using HPSEC and FIFFF with Na-Salt PSS as calibration standard. A significant shift in the elution time of both the organic foulant and the Na-salt of PSS standards were observed during HPSEC fractionation with change in the ionic strength of the carrier solutions. These shifts were due to change in the molecular size of the organic foulant under different ionic strength. However, no significant shift in the elution time was observed with FlFFF fractionation both for organic foulant and Na-salt PSS standards.

\section{Acknowledgements}

This study was funded by Centre for Seawater Desalination Plant (SeaHERO), ARC-DP and the National Research Laboratory Program by the Korea Science and Engineering Foundation (NOM Lab: R0A-2007-00020055-0).

\section{References}

[1] H.K. Shon, S. Phuntsho and S. Vigneswaran, Effect of photocatalysis on the membrane hybrid system for wastewater treatment, Desalination, 225 (2008) 235-248.

[2] J.F. Ranville and C. Muzny, Predicting membrane flux decline using parameters derived from field-flow fractionation measurements. Desalinationa and water purification research and development program. Report No. 102, US Department of Interiors, 2006.

[3] M. Mulder, Basic principles in membrane technology, Kluwer Academic Publishers, 1997.

[4] J. Pellegrino, S. Wright, J. Ranvill and G. Amy, Predicting membrane flux decline from complex istures using flow fieldflow fractionation measurements and semi-empirical theory. Water Science \& Tecnology, 6-7 (2005) 85-92.

[5] C. Pelekani, G. Newcombe, V.L. Snoeyink, C. Hepplewhite, S. Assemi and R. Beckett, Characterization of natural organic matter using high performance size exclusion chromatography. Environmental Science and Technology, 33(16) (1999) 2807-2813.

[6] J.C. Giddings, Field flow fractionation handbook Chapter 1: The field-flow fractionation family: Underlying principles, ed. M. Schimpf, K. Caldwell and J.C. Giddings, Wiley-interscience, 2000.

[7] M.-A. Benincasaa and K.D. Caldwella, Flow field-flow fractionation of poly(ethylene oxide): effect of q carrier ionic strength and composition, Journal of Chromatography A, 925 (2001) 159-169.

[8] L.J. Gimbert, K.N. Andrew, P.M. Haygarth and P.J. Worsfold, Environmental applications of flow field-flow fractionation (FIFFF), Trends in Analytical Chemistry, 22(10) (2003) 615-633.
[9] R.L. Hartmann and S.K.R. Williams, Flow field-flow fractionation as an analytical technique to rapidly quantitate membrane fouling, Journal of Membrane Science, 209 (2002) 93-106.

[10] S. Assemi, G. Newcombe, C. Hepplewhite and R. Beckett, Characterization of natural organic matter fractions separated by ultrafiltration using flow field-flow fractionation, Water Research, 38 (2004) 1467-1476.

[11] R. Beckett, Z. Jue and J.C. Giddings, Determination of molecular weight distributions of fulvic and humic acids using flow fieldflow fractionation, Environmental Science and Technology, 21(3) (1987) 289-295.

[12] M.-A. Benincasaa and J.C. Giddings, Separation and molecular weight distribution of anionic and cationic water-soluble polymers by flow field-flow fractionation, Anal. Chem., 64(7) (1992) 790-798.

[13] J.C. Giddings, F.J. Yang and M.N. Myers, Flow field-flow fractionation as a methodology for protein separation and characterization, Anal. Biochem., 81 (1997) 395-407.

[14] J. Josef and C. Josef, Focusing in field-flow fractionation, Anal. Chem., 56(13) (1984) 2481-2484.

[15] J.C. Giddings, Field-flow fractionation of polymers: one-phase chromatography, Pure \& Appl. Chem., 51 (1979) 1459-1471.

[16] R.L. Wershaw and G.R. Aiken, Molecular Size and Molecular Weight Measurements of Humic Substances, ed. S. In Humic Substances in Soil, and Water, Wiley-Interscience, NewYork, 1985.

[17] P.K. Cornel, R.S. Summers and P.V. Roberts, Diffusion of humic acid in diluted aqueous solution, Journal of Colloid and Interface Science, 110(1) (1986) 149-164.

[18] R.A. Alvarez-Puebla and J.J. Garrido, Effect of $\mathrm{pH}$ on the aggregation of a gray humic acid in colloidal and solid states, Chemosphere, Article in Press, 2004.

[19] R.S. Cameron, B.K. Thornton, R.S. Swift and A.M. Posner, Molecular weight and shape of humic acid from sedimentation and diffusion measurement on fractionated extracts, Journal of Soil Science, 23 (1972) 394-408.

[20] S. Green, F.M. Morel and N.V. Blough, Investigation of the electrostatic properties of humic substances by fluorescence quenching, Environmental Science and Technology, 26(2) (1992) 294-301.

[21] E. Illés and E. Tombácz, The effect of humic acid adsorption on $\mathrm{pH}$-dependent surface charging and aggregation of magnetite nanoparticles, Journal of Colloid and Interface Science, 295 (2006) 115-123.

[22] J.M. Siéliéchi, B.S. Lartiges, G.J. Kayem, S. Hupont, C. Frochot, J. Thieme, J. Ghanbaja, J.B. d'Espinose de la Caillerie, O. Barrès, R. Kamga, P. Levitz and L.J. Michot, Changes in humic acid conformation during coagulation with ferric chloride: Implications for drinking water treatment, Water Research, 42(8-9) (2008) 2111-2123.

[23] J.E.G.J. Wijnhoven, J.-P. Koorn, H. Poppe and W.T. Kok, Influence of injected mass and ionic strength on retention of watersoluble polymers and proteins in hollow-fibre flow field-flow fractionation, Journal of Chromatography A, 732 (1996) 307-315.

[24] J. Moon, S.-H. Kim and J. Cho, Characterizations of natural organic matter as nano particle using flow fieldflow fractionation, Colloids and Surfaces A: Physicochemical and Engineering Aspects, 287 (2006) 232-236. 
[25] L.D. Nghiem and A.I. Schäfer, Fouling autopsy of hollow-fibre MF membranes in wastewater reclamation, Desalination, 188 (2006) 113-121.

[26] E.-M. Gwon, M.-J. Yu, H.-K. Oh and Y.-H. Ylee, Fouling characteristics of NF and RO operated for removal of dissolved matter from groundwater, Water Research, 37 (2003) 2989-2997.

[27] F. Meng, H. Zhang, F. Yang and 1. Liu, Characterization of cake layer in submerged membrane bioreactor. Environ. Sci. Technol., 41(11) (2007) 4065-4070.

[28] W. Yuan and A.L. Zydney, Humic acid fouling during microfiltration, Journal of Membrane Science, 157 (1999) 1-12.

[29] T. Tran, B. Bolto, S. Gray, M. Hoang and E. Ostarcevic, An autopsy study of a fouled reverse osmosis membrane element used in a brackish water treatment plant, Water Research, 41 (2007) 3915-3923.

[30] E.E.A. Ghafour, Enhancing RO system performance utilizing antiscalants, Desalination, 153 (2003) 149-153.

[31] A. Barghetta, F.A. DiGiano and W.P. Ball, Nanofiltration of natural organic matter: $\mathrm{pH}$ and ionic strength effects, Journal of Environmental Engineering, 123(7) (1997) 628-648.

[32] K. Tsutsuki and S. Kuwatsuka, Molecular size distribution of humic acids as affected by ionic strength and the degree of humification, Soil Science Plant Nutrition, 30 (1984) 151-162.

[33] M.H. Moon, Effect of carrier solutions on particle retention in flow fleid-flow fractionation, Bull. Korean Chem. Soc., 16(7) (1995) 613. 